\title{
Addressing asthma and obesity in children with community health workers: proof-of- concept intervention development
}

\author{
Molly A Martin ${ }^{1 *}$, Steven K. Rothschild ${ }^{2}$, Elizabeth Lynch², Katherine Kaufer Christoffel ${ }^{3}$, Militza M. Pagán ${ }^{4}$, \\ Jose Luis Rodriguez ${ }^{5}$, Anna Barnes ${ }^{3}$, Kelly Karavolos ${ }^{2}$, Antonieta Diaz ${ }^{6}$, Lucretia M. Hoffman7, Diana Plata ${ }^{8}$ \\ and Sandra Villalpando ${ }^{9}$
}

\begin{abstract}
Background: The objective of this study was to design and test the feasibility and impact of a community health worker (CHW) intervention for comorbid asthma and obesity.

Methods: Using a proof of concept study design, we collected pre/post outcomes from a single intervention cohort of urban low-income in a single community area. A community-based participatory research approach was employed. Forty-six children and their caregivers were recruited. Children were 5-12 years old with physician-diagnosed asthma and body mass index $(\mathrm{BMI})>85 \%$. Families were offered 12 home visits from CHWs that integrated asthma and obesity core curriculums. The primary asthma outcome was asthma control, measured via the Childhood Asthma Control Test (CACT). The primary obesity outcome was child body mass index (BMI).

Results: Families received a median of 10 out of the 12 home visits over 1 year. At 1 year, there was a significant improvement in the number of children with controlled asthma as measured via CACT ( $85.7 \%$ at 1 year compared to $61.9 \%$ at baseline, $p=0.01$ ). Activity limitations and emergency utilization were reduced while inhaler technique improved ( $p<0.01$ for all). Child BMI z-score was reduced: mean $=1.97($ SD 0.79) at 1 year compared to mean $=2.13$ (SD 0.40) at baseline, $p<0.01$. No association was seen between change in child BMl and change in asthma control. Worse baseline child depression scores were associated with less improvement in asthma control $(p=0.003)$ and higher baseline caregiver post-traumatic stress disorder scores were associated with increased child BMI $(p=0.012)$.
\end{abstract}

Conclusions: The CHW intervention has promise for improving asthma and weight outcomes in high-risk children with comorbid asthma and obesity; this model warrants further development and investigation.

Keywords: Asthma, Obesity, Pediatrics, Community health worker

\section{Background}

Obesity constitutes an important risk factor for asthma. Asthma prevalence is higher in overweight and obese children $[1,2]$ and obesity frequently precedes asthma development, suggesting a causal role [3, 4]. Obese children with asthma use more medicine, wheeze more, and have more unscheduled emergency department visits than nonobese children with asthma [4].

\footnotetext{
* Correspondence: mollyma@uic.edu

${ }^{1}$ University of Illinois at Chicago, 840 South Wood Street, M/C 856, Chicago, IL 60612, USA

Full list of author information is available at the end of the article
}

Despite these strong associations, interventions targeting children with both asthma and obesity are limited [5-9]. This gap in the field prompted the formation of the Community United to Raise Awareness: Asthma and Active Living study (CURA 2) with the goal of developing a behavioral intervention for children with both asthma and obesity. The home-based intervention used a community health worker $(\mathrm{CHW})$ asthma model that had previously been tested in the target community [10]. The intervention was strengthened by increasing the dose and duration, and by adding pediatric obesity modules. The CURA 2 intervention was then tested in a proof of concept study to assess if these changes resulted in a feasible 
intervention that could improve asthma control and reduced body mass index (BMI).

\section{Methods}

\section{Theoretical model}

This study is part of the Rush Center for Urban Health Equity which adapts the Warnecke model for population health disparities [11]. Proximal, intermediate, and distal factors and their contributions to disparities are considered. The portion of the CURA 2 study described in this manuscript focused on the home and aimed to address family social relationships, risk behaviors, psychosocial factors, and the physical environment. Other study phases not described here targeted schools. Social Cognitive Theory guides the CHW intervention [12]. Behavior is shaped and maintained by consequences, particularly by immediate feedback from both objective sources (such as observation of inhaler technique or home triggers) and an individual's social network (beliefs and traditions of family and friends). The asthma CHW home intervention measures and supports these behaviors and social networks using self-management skills (selfmonitoring, social support, environmental rearrangement, problem solving, and behavior change plans).

\section{Study design}

This proof of concept study was uncontrolled with data collection at baseline (pre) and 12-months (post) in the homes by research assistants (RAs), and $12 \mathrm{CHW}$ home visits offered over the 12-month intervention period. A community-based participatory research approach was employed to design and oversee the study. The study built off of partnerships developed in previous research in a low income community area in Chicago with high documented asthma prevalence and morbidity [10, 13]. The study team included clinician researchers with expertise in behavioral interventions, asthma, obesity, and child development. Community partners on the study team included a local health coalition (Greater Humboldt Park Community of Wellness), a social service organization (Puerto Rican Cultural Center), a parent-led service organization (Women Living with Hope), and an obesity advocacy organization (Consortium to Lower Obesity in Chicago Children).

The recruitment goal for this uncontrolled cohort was 30-50 children that met the following inclusion criteria: 5-12 years old, residence within defined geographic boundaries, physician-diagnosed asthma (per caregiver report), overweight or obese (BMI $>85 \%$ ), and not attending a school with a planned subsequent school-level intervention. Participants were recruited via community events, schools, and local clinics. Written informed consent from caregivers and child assent were obtained in the home by research assistants in the family's preferred language
(English or Spanish). The study was approved by the Rush University Medical Center Institutional Review Board and Chicago Public Schools Research Review Board.

\section{Outcomes}

Outcomes were assessed by bilingual RAs in the home at baseline and 12-months. Survey questions were asked verbally to the caregiver/child with the exception of the mental health instruments which were self-administered. Families received $\$ 50$ both at the baseline and 12-month data collections for a total of $\$ 100$ by the end of the study.

\section{Asthma control}

Asthma control was determined using the Childhood Asthma Control Test (cACT) [14]. A score of $>19$ is considered uncontrolled [14]. The Expert Panel Report 3 guidelines to assess control using questions on symptoms, medication usage, missed activities, and prednisone use were also used [15]. Families self-reported emergency department visits and hospitalizations.

\section{Asthma medications}

RAs asked to see all of the children's asthma medications. For children with an inhaled corticosteroid (ICS), adherence was determined using a medication dose counter placed on the inhaler that documented the number of times the inhaler was actuated daily (Doser CT, MediTrack, Inc., South Easton, MA) or using the ICS canister's integrated dose counter $[10,16]$. Children were asked to demonstrate their medication technique [17].

\section{Home triggers}

Home asthma trigger data were obtained by caregiver report, a visual home assessment, and objective measurement [18]. Families were asked about behaviors related to allergens such as dust mites, pets, roaches and rodents, and exposures to irritants such as cigarette smoke. The visual home assessment included visual and olfactory examination of the child's bedroom, main living area, kitchen, bathroom, and heating source. Saliva was taken from children and tested for cotinine with an ELISA using a high sensitivity quantitative immunoassay (Salimetrics, Inc, State College, PA), with calibrator range 0.8$200 \mathrm{ng} / \mathrm{mL}$, sensitivity $0.05 \mathrm{ng} / \mathrm{mL}$. Salivary cotinine levels ranging from 1-7 ng/ml were coded as environmental tobacco smoke (ETS) exposure [19]. A positive report of a trigger from any one of the three data sources resulted in a positive score for that trigger.

\section{Allergen sensitivity}

Aeroallergen sensitivity of children was assessed in the home at baseline using the ImmunoCAP ${ }^{\circ}$ Rapid Inhalant Profile 1, an in vitro semi-quantitative assay for measurement of allergen specific IgE in whole blood 
(http://www.phadia.com/en/Products/Allergy-testingproducts/ImmunoCAP-Rapid/).

\section{Child and caregiver anthropometrics}

Height was measured using a tape measure and straight edge. Weight was measured using a calibrated portable digital scale. BMI was calculated as kilograms/meters squared using CDC age/sex specific growth charts formulas.

\section{Child and caregiver hemoglobin A1c and lipid profiles}

One caregiver per family and the child were asked to fast before the data collection visit, and blood was collected using dried blood kits. Hemoglobin A1c assays were performed using a standard procedure developed by ZRT laboratory [20]. Lipid profiles were measured using commercial kits (Randox Laboratory, UK) and reagents (e.g., enzymatic reagents, standards and control sera) [21].

\section{Child physical activity}

Children wore ActiGraph Accelerometers (GT1M and GT3X units) around their waists. Accelerometers were set for $15 \mathrm{~s}$ epochs and were worn for a minimum of $10 \mathrm{~h} /$ day for 4 days (including 1 weekend day). Physical activity levels were set using the Evenson cut points [22]. Children (or caregivers for children under 8) also completed a 7 day physical activity recall [23].

\section{Home food environment}

Visual inspection of the home food environment for obesogenic foods was conducted using the Home Food Inventory [24]. Caregivers were asked nutrition behavior questions from the Family Nutrition and Physical Activity screening tool [25]. Food security was assessed using the USDA Food Security Survey [26].

\section{Other}

Sleep disordered breathing was assessed using the snoring portion of the Pediatric Sleep Questionnaire [27]. Caregivers were asked about self-efficacy for asthma management using the Parent Asthma SelfEfficacy Scale [28]. A similar 10-item scale about selfefficacy nutrition and physical activity was created. Caregivers were screened for depression symptoms using the PHQ-9 [29] and for trauma using the Short Form of the PTSD Checklist - Civilian Version [30]. Children were screened for depression using the Child Depression Inventory 2 Short Form [31].

\section{Intervention}

CHWs were trained by investigators using a $40 \mathrm{~h}$ curriculum that contained established asthma training [10] and newly created pediatric obesity modules (http://
cuhe.rush.edu/Cura\%202/Pages/CommunityHealthWorker Training.aspx.) Families were offered 12 home visits over 12 months from CHWs. Each home visit was expected to last about $60 \mathrm{~min}$. Visits began with several minutes of social discussion for the purpose of connection. The CHWs approached each visit with the intention to teach one or two of the core curriculum topics (Table 1). The order of topics was developed based on the individual family's interest and needs. The asthma and obesity curriculum topics were interconnected to address potential conflicts in messaging. For example, when discussing steroid medications, CHWs strongly emphasized that these are not the steroids associated with weight gain. When a CHW noted a barrier in the delivery or understanding of the education, she applied self-management skills. Behavior change plans were reviewed and new plans made at the end of each visit; behavior change plans are small goals for a specific change over a 2-week period. Examples include: "getting a prescription from my doctor" or "increasing exercise by $5 \mathrm{~min}$ a day".

\section{Analysis}

Basic summary statistics were calculated for baseline variables. Changes in the primary outcome of asthma control (cACT) from baseline to 1 year were assessed using McNemar's exact test or paired samples $t$-test. Regression models were used to test the influence of dose, BMI, and baseline variables on primary asthma outcomes. Asthma secondary variables (Table 2) were tested for change from baseline to 1 year using McNemar's exact test or t-test. Finally, variables with statistically significant changes were included in mediation analyses to determine their influence on primary asthma outcomes. These same series of analyses were repeated with the obesity primary outcome (child BMI z-score) and obesity secondary variables (Table 2).

Table 1 Community health worker home visit topics

\begin{tabular}{|c|c|c|}
\hline $\begin{array}{l}\text { Asthma Core } \\
\text { Curriculum }\end{array}$ & $\begin{array}{l}\text { Obesity Core } \\
\text { Curriculum }\end{array}$ & $\begin{array}{l}\text { Self-Management } \\
\text { Skills }\end{array}$ \\
\hline General asthma facts & General obesity facts & Problem solving \\
\hline Controller medications & Healthy foods & Social support \\
\hline Inhalers and spacers & Beverages & $\begin{array}{l}\text { Environmental } \\
\text { rearrangement }\end{array}$ \\
\hline Symptom recognition & Portions and labels & Self-monitoring \\
\hline Asthma triggers & Physical activity & \\
\hline $\begin{array}{l}\text { Communicating with } \\
\text { providers }\end{array}$ & Screen time & \\
\hline Asthma and schools & $\begin{array}{l}\text { Communicating with } \\
\text { providers }\end{array}$ & \\
\hline Asthma and obesity & Obesity and schools & \\
\hline
\end{tabular}


Table 2 Clinical characteristics $(N=46)$

\begin{tabular}{|c|c|}
\hline \multicolumn{2}{|l|}{ Asthma control } \\
\hline$C A C T$, mean (SD) & $20.9(3.6)$ \\
\hline CACT <20 (uncontrolled), N (\%) & $18(40.0)$ \\
\hline \multicolumn{2}{|l|}{ Uncontrolled in last 30 days, N (\%) } \\
\hline Day symptoms & $17(37.0)$ \\
\hline Night symptoms & $23(50.0)$ \\
\hline Excess quick reliever use & $16(34.8)$ \\
\hline Activity limitations & $16(34.8)$ \\
\hline \multicolumn{2}{|l|}{ Healthcare utilization for asthma over last 12 months, N (\%) } \\
\hline Emergency room & $15(32.6)$ \\
\hline Hospitalization & $6(13.0)$ \\
\hline Prednisone/prednisolone use & $12(26.1)$ \\
\hline \multicolumn{2}{|l|}{ Medications } \\
\hline Have a quick relief medication, $\mathrm{N}(\%)$ & $29(63.0)$ \\
\hline Have an inhaled corticosteroid, N (\%) & $20(43.0)$ \\
\hline Puffs/day inhaled corticosteroid, median (25th, 75th percentile) & $0.6(0.2,1.4$ \\
\hline Have a spacer, N (\%) & $16(34.8)$ \\
\hline Percent correct technique, mean (SD) & $58(18.3)$ \\
\hline \multicolumn{2}{|l|}{ Tobacco exposure, N (\%) } \\
\hline Self-reported smoker in the home & $21(45.7)$ \\
\hline Cotinine level >1.0 & $11(23.9)$ \\
\hline \multicolumn{2}{|l|}{ Home triggers, $N(\%)$} \\
\hline Working vacuum & $23(50.0)$ \\
\hline Dogs & $17(37.0)$ \\
\hline Cats & $4(8.7)$ \\
\hline Problem with roaches & $18(39.1)$ \\
\hline Problem with rats/mice & $14(30.4)$ \\
\hline Problem with mold & $22(47.8)$ \\
\hline \multicolumn{2}{|l|}{ Allergen sensitivity, N (\%) } \\
\hline Dog & $6(18.0)$ \\
\hline Cat & $8(24.0)$ \\
\hline Dust mite 1 (D. pteronyssinus) & $14(42.0)$ \\
\hline Dust mite 2 (D. farina) & $13(39.0)$ \\
\hline \multicolumn{2}{|l|}{ Child anthropometrics } \\
\hline Overweight (BMI 85-95\%), N (\%) & $7(15)$ \\
\hline Obese (BMI $\geq 95 \%), \mathrm{N}(\%)$ & $39(84)$ \\
\hline \multicolumn{2}{|l|}{ Child, ${ }^{\mathrm{a}} \mathrm{N}(\%)$} \\
\hline Hemoglobin A1c borderline high (5.7-6.4) & $16(36)$ \\
\hline Hemoglobin A1c elevated $(\geq 6.5)$ & $1(2)$ \\
\hline LDL cholesterol borderline high (110-129) & $4(9)$ \\
\hline LDL cholesterol elevated $(\geq 130)$ & $6(13)$ \\
\hline HDL cholesterol borderline low (40-45) & $8(18)$ \\
\hline HDL cholesterol low $(<40)$ & $18(40)$ \\
\hline Triglycerides borderline high ${ }^{\text {b }}$ & $6(13)$ \\
\hline Triglycerides elevated $^{\mathrm{b}}$ & $29(64)$ \\
\hline
\end{tabular}

Table 2 Clinical characteristics ( $N=46)$ (Continued)

\begin{tabular}{|c|c|}
\hline \multicolumn{2}{|l|}{ Child physical activity } \\
\hline $\begin{array}{l}\text { Minutes of moderate/vigorous physical activity, } \\
\text { median (25th, 75th percentile) }\end{array}$ & $39(29,59)$ \\
\hline Physical activity 60 min/day, N (\%) & $10(21.7)$ \\
\hline Self-reported physical activity, ${ }^{c}$ mean (SD) & $2.8(0.7)$ \\
\hline Caregiver obese (BMI $\geq 30), \mathrm{N}$ (\%) & $28(60.9)$ \\
\hline \multicolumn{2}{|l|}{ Caregiver, ${ }^{\mathrm{d}} \mathrm{N}(\%)$} \\
\hline Hemoglobin A1c elevated ( $\geq 6.5)$ & $10(31)$ \\
\hline LDL cholesterol elevated $(\geq 160)$ & $2(5)$ \\
\hline HDL cholesterol low $(<40)$ & $10(23)$ \\
\hline Triglycerides elevated $(\geq 200)$ & $17(39)$ \\
\hline Child screen time $>2$ hrs/day, N (\%) & $43(93.5)$ \\
\hline $\begin{array}{l}\text { Child seems to stop breathing at night (obstructive } \\
\text { sleep apnea), N (\%) }\end{array}$ & $10(21.7)$ \\
\hline \multicolumn{2}{|l|}{ Food security, N (\%) } \\
\hline Marginal & $10(23.0)$ \\
\hline Low/very low & $23(50.0)$ \\
\hline Percent of home food obesogenic, mean (SD) & $35(14)$ \\
\hline Self-reported family nutrition in high risk category, N (\%) & $14(30.4)$ \\
\hline \multicolumn{2}{|c|}{$\begin{array}{l}\text { a } N=45 \\
\text { b Age 0-9: } 75-99=\text { borderline high, } \geq 100=\text { elevated. Age } 10-19: 90-129= \\
\text { borderline high, } \geq 130=\text { elevated } \\
\text { cA score of } 1 \text { indicates low physical activity, whereas a score of } 5 \text { indicates } \\
\text { high physical activity } \\
\text { d } N=44\end{array}$} \\
\hline
\end{tabular}

The participating families $(N=46)$ were primarily low income and Hispanic which reflects the demographics of the target community (Table 3). Their clinical data are shown in Table 2 . While only $40 \%$ of children had cACT scores indicating poor asthma control over the past 30 days, $74 \%$ were uncontrolled over the past year based on the EPR3 guidelines for control that include emergency room or hospitalization. Inhaled corticosteroid presence was low (43\%) but only persistent asthma requires these medications. Quick relief medicines are essential for all children with asthma; however, $37 \%$ of children did not have a quick relief medication and $65 \%$ did not have a spacer. Technique with their devices was suboptimal. Across all devices, the mean number of demonstrated correct steps for usage was $58 \%$ (SD 18.3). Triggers in the home were common, as were allergies to common triggers. Almost a quarter of children had cotinine levels suggesting recent ETS exposure. The majority of children were obese $(84 \%)$ and the rest overweight. Screen time exceeded recommendations $(93.5 \%$ reported more than two hours per day) and few children (22\%) met the requirements for $60 \mathrm{~min} /$ day of moderate/vigorous physical activity.

Many psychosocial stressors were identified. Among caregivers, $28.9 \%$ had symptoms of moderate-to-severe 
Table 3 Baseline demographics $(N=46)$

\begin{tabular}{|c|c|}
\hline \multicolumn{2}{|l|}{ Caregiver } \\
\hline Female, N (\%) & $44(95.7)$ \\
\hline Age, mean (SD) & $37.9(7.6)$ \\
\hline Years of school completed, median (Q1, Q3) & $12(9,13)$ \\
\hline Hispanic, $N^{a}(\%)$ & 39 (84.8) \\
\hline Mexican & $19(48.7)$ \\
\hline Puerto Rican & $16(41.0)$ \\
\hline Other Hispanic & $3(7.7)$ \\
\hline Refuse & $1(2.2)$ \\
\hline \multicolumn{2}{|l|}{ Race, $N^{a}(\%)$} \\
\hline Black/non-Hispanic & $7(15.2)$ \\
\hline White/non-Hispanic & $3(6.5)$ \\
\hline Other & $37(80.4)$ \\
\hline \multicolumn{2}{|l|}{ Place of birth, N (\%) } \\
\hline United States & $18(39.1)$ \\
\hline Mexico & $15(32.6)$ \\
\hline Puerto Rico & $10(21.7)$ \\
\hline Other & $3(6.5)$ \\
\hline If not born in US, years on mainland US, median (Q1, Q3) & $15.5(12,24)$ \\
\hline \multicolumn{2}{|l|}{ Income, N (\%) } \\
\hline$<\$ 5,000$ & $9(19.6)$ \\
\hline$\$ 5,000-\$ 14,999$ & $12(26.0)$ \\
\hline$\$ 15,000-\$ 19,999$ & $14(30.4)$ \\
\hline$\$ 20,000-\$ 59,999$ & $11(23.9)$ \\
\hline \multicolumn{2}{|l|}{ Home ownership, N(\%) } \\
\hline Own outright/mortgage & $5(10.9)$ \\
\hline Rent & $36(78.3)$ \\
\hline Live with others rent free & $4(8.7)$ \\
\hline Other & $1(2.2)$ \\
\hline \multicolumn{2}{|l|}{ Marital Status, N(\%) } \\
\hline Married/live with partner & $25(54.3)$ \\
\hline Single & $18(39.1)$ \\
\hline Separate/Divorced/Widowed & $3(7.7)$ \\
\hline \multicolumn{2}{|l|}{ Child } \\
\hline Age, mean (SD) & $9.7(2.2)$ \\
\hline Female, N (\%) & $31(67.4)$ \\
\hline Grade, median (Q1, Q3) & $4(2,5)$ \\
\hline \multicolumn{2}{|l|}{ Place of birth, N (\%) } \\
\hline United States & $42(91.3)$ \\
\hline Mexico & $1(2.2)$ \\
\hline Puerto Rico & $3(6.5)$ \\
\hline Child health insurance Medicaid, N (\%) & $44(95.7)$ \\
\hline
\end{tabular}

${ }^{a}$ For race and ethnicity, participants were allowed to endorse multiple categories if they applied depression, 66\% had experienced at least one traumatic life event, and $33.8 \%$ screened positive for probable PTSD. In children, 5.3\% had depression scores in the "high average" range while $13.2 \%$ in the "elevated" range.

Families received a median of 10 out of the 12 home visits over 1 year (Fig. 1). Three families refused all home visits; one of these refused the 1 year data collection as well. Two other families accepted CHW visits but refused the 1 year data collection. As shown in Table 4, there was a significant improvement in children with controlled asthma as measured via CACT $(85.7 \%$ at 1 year compared to $61.9 \%$ at baseline, $p=0.01$ ) but this represented only a mean change in cACT score of 1.9 (SD 4.4). The minimally important difference for the cACT is 2 [32]. Activity limitations were reduced ( $7 \%$ at 1 year compared to $32.6 \%$ at baseline, $p=0.002$ ) and emergency department/hospital use decreased $(27.9 \%$ at 1 year compared to $53.5 \%$ at baseline, $p=0.003)$. Inhaler technique improved $(90 \%$ correct at 1 year compared to $60 \%$ at baseline, $p<0.01)$. Child BMI zscore was reduced at 1 year: mean $=1.97(\mathrm{SD} 0.79)$ at 1 year compared to mean $=2.13$ (SD 0.40) at baseline, $p<0.01$. The number of $\mathrm{CHW}$ home visits received was weakly associated with healthcare utilization at 1 year $(p=$ 0.049 ) but no other asthma outcomes were associated with number of visits received. Also, no association was seen between change in child BMI and change in asthma control $(p=0.188)$.

Secondary analyses were conducted to better understand the primary outcomes. None of the baseline asthma and obesity supporting variables predicted change in asthma control or child BMI. However, worse baseline child depression scores were associated with less improvement in asthma control $(p=0.003)$ and higher baseline caregiver PTSD scores were associated with more child BMI change in the direction of weight gain $(p=0.012)$. Many of the supporting variables did improve over the year, including nighttime asthma symptoms $(p=0.041)$, activity limitation $(p=0.002)$ ED/hospitalizations $(p=$ $0.003)$, inhaler technique $(p<0.001)$, child hemoglobin A1c $(p=0.027)$, child HDL cholesterol $(p=0.013)$, and sleep disordered breathing $(p=0.027)$. Although caregivers were not the focus of the intervention, they gained weight (baseline BMI mean $=34.8$, SD 9.6; 1 year BMI mean = 36.2 , SD 10.1; $p=0.008)$ while showing improvements in hemoglobin A1c $(p=0.012)$ and HDL cholesterol $(p=$ $0.036)$. However, none of the supporting variables that showed positive changes over the year mediated child asthma control or BMI. Caregiver depression decreased from baseline to 1 year (PHQ9 baseline mean $=7.5$, SD $7.1 ; 1$ year mean $=5.6, \mathrm{SD} 6 ; p=0.039$ ). Change in caregiver depression score was weakly associated with change in child BMI z-score $(p=0.079)$ but not asthma control. 


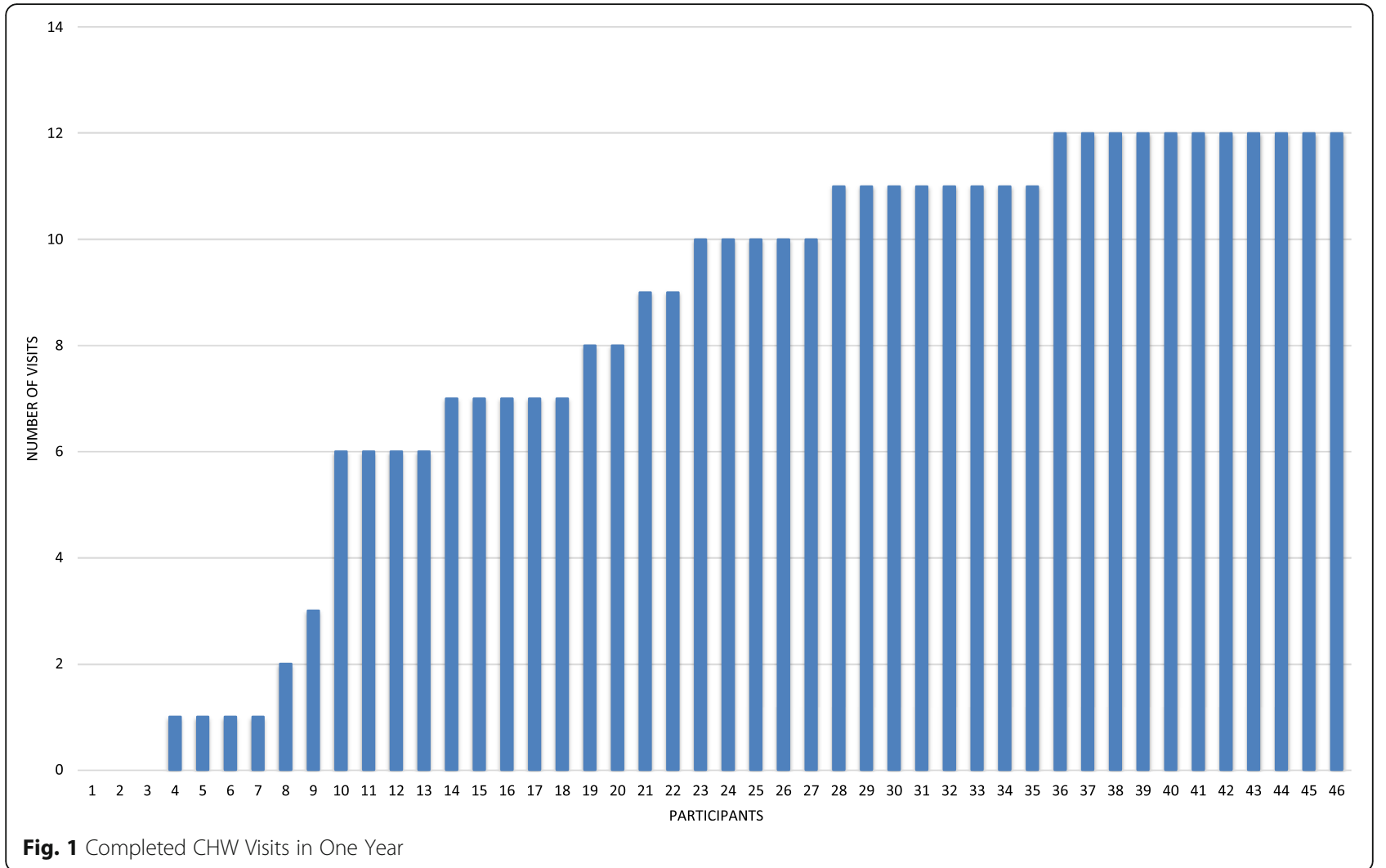

\section{Discussion}

CURA 2 sought to test the feasibility of a home CHW intervention targeting both asthma and obesity, and to generate estimates for the potential of this intervention to improve child asthma control and BMI. The CHW intervention was well received. Only three families refused the CHW home visits. We strove to deliver 12 home visits but only $30 \%$ were able to complete all 12 , and that was with difficulty. The primary content was intended to be delivered in visits one through ten, with visits 11-12 used for review and reinforcement. For asthma CHW intervention alone, Postma et al found that six visits were acceptable [33]. Campbell et al. showed that four home visits were associated with improved outcomes and a significant return on investment [34]. Because CURA 2 combined both asthma and obesity content, we suggest 10 home visits in a year would have been a more feasible goal.

While efficacy of the intervention cannot be definitively determined due to limited power and a lack of a control group, comparison of pre/post data suggest a possible benefit for asthma. The asthma control score, nighttime symptoms, activity limitations, ED/hospitalizations, and medication technique all improved at 1 year. However, the change in asthma control was modest and some of the children seemed to have mild intermittent controlled asthma from the start. Medication use and triggers in the home did not change, making it difficult to understand how changes in asthma occurred and whether they can be attributed to the intervention. Observed changes may simply be a result of natural improvements in asthma control as children grow. Future studies should consider restricting their sample to children with uncontrolled persistent asthma to reduce these limitations.

The outcomes for obesity were more robust. As children approach adolescence, it is typical for BMI to increase [35]. However, CURA 2 study participants had an overall decrease in BMI. A 0.25 BMI Z-score reduction is associated with reduced inflammation and improved insulin sensitivity in children; [36] the mean reduction in this study was 0.16 . We saw some improvements at 1 year in markers of diabetes and lipids (for children and their caregivers) as well as obstructive sleep apnea, but we did not see anticipated changes in food environment, screen time, or activity level. The CHW intervention targeted healthy foods, screen time and physical activity as steps toward weight management which makes the mechanism for BMI reduction more difficult to understand and limits our ability to attribute it to the intervention.

Several key barriers to implementing the asthma control and obesity reduction strategies were identified. The first was lack of communication between the CHWs and clinical providers. CHWs (and potentially providers) could have 
Table 4 Primary and secondary outcomes

\begin{tabular}{|c|c|c|c|}
\hline & Baseline & One Year & $P$ value \\
\hline \multicolumn{4}{|l|}{ Asthma } \\
\hline \multicolumn{4}{|l|}{ Asthma Control } \\
\hline$C A C T^{a}<20$ & $16(38.1 \%)$ & $6(14.3 \%)$ & 0.013 \\
\hline Uncontrolled day symptoms & $16(37.2 \%)$ & $10(23.3 \%)$ & 0.109 \\
\hline Uncontrolled night symptoms & $21(48.8 \%)$ & $11(25.6 \%)$ & 0.041 \\
\hline Excess quick reliever use & $14(32.6 \%)$ & $13(30.2 \%)$ & 0.819 \\
\hline Activity limitations & $14(32.6 \%)$ & $3(7.0 \%)$ & 0.002 \\
\hline ED/hospitalization in past year & $23(53.5 \%)$ & $12(27.9 \%)$ & 0.003 \\
\hline Asthma self-efficacy, mean (SD) & $4.1(0.8)$ & $4.4(0.5)$ & 0.006 \\
\hline Inhaler technique (\% of steps correct), mean (SD) & $60 \%(20)$ & $90 \%(10)$ & $<0.001$ \\
\hline \multicolumn{4}{|l|}{ Obesity } \\
\hline \multicolumn{4}{|l|}{ Weight control } \\
\hline BMI z-score, ${ }^{a}$ mean (SD) & $2.13(0.40)$ & $1.97(0.70)$ & 0.002 \\
\hline BMI percentile, mean (SD) & $97.6(2.2)$ & $96.1(4.4)$ & 0.011 \\
\hline Obese (BMI $\geq 95 \%)$ & $84 \%$ & $74 \%$ & \\
\hline Nutrition self-efficacy, mean (SD) & $3.6(0.8)$ & $3.9(0.7)$ & 0.007 \\
\hline Child hemoglobin A1c, mean (SD) & $5.6(1)$ & $5.3(1.2)$ & 0.027 \\
\hline Child HDL cholesterol, mean (SD) & $44.9(12.3)$ & $52.3(12.7)$ & 0.013 \\
\hline Child sleep disordered breathing, mean (SD) & $2(2)$ & $1.5(1.8)$ & 0.027 \\
\hline Caregiver BMI, mean (SD) & $34.8(9.6)$ & $36.2(10.1)$ & 0.008 \\
\hline Caregiver hemoglobin A1C, mean (SD) & $6(1.3)$ & $5.6(1.8)$ & 0.012 \\
\hline Caregiver HDL cholesterol, mean (SD) & $50.2(11.4)$ & $54.7(9.4)$ & 0.036 \\
\hline
\end{tabular}

Primary outcomes

No significant changes from baseline to one year for presence of a quick relief or controller medication, controller medication adherence, prednisone use, cotinine level, observed triggers in the home, self-reported physical activity, screen time, accelerometry, food security, self-reported food in the home, observed obesogenic food in the home, child triglyceride, child LDL cholesterol, caregiver triglycerides, and caregiver LDL cholesterol

benefitted from the ability to discuss care plans with providers. Second, mental health issues were prevalent; caregivers endorsed high levels of trauma and depression, and these variables appeared to have mediating effects on child BMI. Poorer psychological functioning has been associated with increased asthma morbidity [37] and similar associations are also seen in obesity $[38,39]$. The impact of the CHW intervention on psychological functioning remains unclear [40] and requires further investigation.

\section{Conclusions}

While the small sample size and lack of a control group limits our interpretation of intervention effects, we demonstrated feasibility and potential effects of a CHW intervention for children with both asthma and obesity. $\mathrm{CHW}$ asthma interventions have already shown benefits in asthma symptom control and healthcare utilization [41]. Our study is novel in that the intervention targets a subpopulation of children with both asthma and obesity. These children typically suffer worse asthma morbidity and their asthma is more challenging to control, $[1,2]$ yet few studies have published interventions specifically targeting these children [5-9]. None of these used CHWs and no pediatric obesity CHW training curriculum had been published to date. Therefore we created a curriculum, merged it with asthma training, and then delivered the combined asthma/obesity intervention to a high risk cohort of urban children and their families. For asthma medication adherence, medication technique, and triggers, outcomes were measured objectively; this limits the sometimes inaccurate results generated from self-reported data. The measured changes in asthma control and child BMI, while not large, warrant further study. Our small study could not address the full spectrum of social, behavioral, and environmental contributors to asthma and obesity $[11,41]$. However our findings suggest that the CURA 2 CHW intervention, which could be expanded to include clinical and community partners and mental health resources, has promise for improving asthma and weight outcomes in the high-risk population of children with comorbid asthma and obesity. 


\section{Abbreviations}

CURA 2: Community united to raise awareness: asthma and active living: BMl: Body mass index; CACT: Childhood asthma control test; CHW: Community health worker; ETS: Environmental tobacco smoke; ICS: Inhaled corticosteroid; PTSD: Post-traumatic stress disorder; RAs: Research assistants

\section{Acknowledgements}

This study is part of the Rush Center for Urban Health Equity which is funded by the National Institutes of Health $(\mathrm{NIH})$ through the National Institute for Heart Lung and Blood (NHLBI), grant number 1P50HL105189-01. The content of this manuscript is solely the responsibility of the authors and does not necessarily represent the official views of the NIH or NHLBI. The authors would like to thank the rest of the co-investigators and staff: Gilma Arguello, Jaime Arteaga, Rosalinda Campos, Rose de Jesus, Sheila Dugan, Dora Flores-Albert, Eleanor Floyd, Matt Greve, Hong Li, Lolita Lopez, Dorian Ortega, Sara Nixon, Janet Rocha, Madeleine Shalowitz, Serina Silvestry, Julio Urrutia, Sandra Villalpando, and Grant Vitale. We would like to thank the Rush Center for Urban Health Equity Principal Investigator Lynda H Powell, and Director of the Data Core DeJuran Richardson. We also want to thank our fantastic Community Advisory Board and our partners: The Puerto Rican Cultural Center, Women Living with Hope, the Greater Humboldt Park Community of Wellness, and the Consortium to Lower Obesity in Chicago Children. Finally, thanks to the many other organizations, schools, and families who made this study possible.

\section{Funding}

This study is part of the Rush Center for Urban Health Equity which is funded by the National Institutes of Health $(\mathrm{NIH})$ through the National Institute for Heart Lung and Blood (NHLBI), grant number 1P50HL105189-01. The content of this manuscript is solely the responsibility of the authors and does not necessarily represent the official views of the $\mathrm{NIH}$ or NHLBI.

\section{Availability of data and materials}

The datasets analyzed during the current study are available from the corresponding author or from Rush University Medical Center Department of Preventive Medicine on reasonable request.

\section{Authors' contributions}

All authors contributed to the preparation of this manuscript and have approved it. The following authors participated in study design, implementation, and analysis: MAM, SKR, EL, KKC, MLP, JLR, AB. The following authors participated in data analysis: KK, DP. AD contributed to study implementation and analysis. LH and SV contributed to parts of study design and implementation.

\section{Competing interests}

The authors declare that they have no competing interests.

\section{Consent for publication}

Not applicable.

\section{Ethics approval and consent to participate}

The study was approved by the Rush University Medical Center Institutional Review Board and Chicago Public Schools Research Review Board. All adult subjects provided written informed consent. Children with sufficient literacy and age 7 or older provided written assent.

\section{Author details}

${ }^{1}$ University of Illinois at Chicago, 840 South Wood Street, M/C 856, Chicago, IL 60612, USA. ${ }^{2}$ Rush University Medical Center, 1700 W Van Buren, Suite 470, Chicago, IL 60612, USA. 'urie Children's Hospital, 225 E Chicago Ave, Chicago, IL 60611, USA. ${ }^{4}$ Puerto Rican Cultural Center, 2700 W Haddon Ave, Chicago, IL 60622, USA. ${ }^{5}$ Greater Humboldt Park Community of Wellness, 1116 N. Kedzie, Chicago, IL 60651, USA. 'University of Illinois at Chicago, Jane Addams College of Social Work, 1040 West Harrison Street, Chicago, IL 60607, USA. ${ }^{7}$ Forsyth County Department of Public Health, 201 N Chestnut St, Winston-Salem, NC, USA. ${ }^{8}$ Rush University Medical Center, College of Medicine, 600 S Paulina St, Chicago, IL 60612, USA. ${ }^{9}$ University of Illinois at Chicago, College of Medicine, 808 S Wood St, Chicago, IL 60612, USA.
Received: 1 July 2015 Accepted: 29 November 2016

Published online: 01 December 2016

\section{References}

1. Belamarich PF, Luder $E$, Kattan $M$, et al. Do obese inner-city children with asthma have more symptoms than nonobese children with asthma? Pediatrics. 2000;106(6):1436-41.

2. Halfon N, Larson K, Slusser W. Associations between obesity and comorbid mental health, developmental, and physical health conditions in a nationally representative sample of US children aged 10 to 17. Acad Pediatr. 2013;13(1):6-13.

3. Chen YC, Dong GH, Lin KC, et al. Gender difference of childhood overweight and obesity in predicting the risk of incident asthma: a systematic review and meta-analysis. Obes Rev. 2012;13 Suppl 3:222-31.

4. Shore SA. Obesity and asthma: possible mechanisms. J Allergy Clin Immunol. 2008;121(5):1087-93.

5. Adeniyi FB, Young T. Weight loss interventions for chronic asthma. Cochrane Database Syst Rev. 2012;7:CD009339.

6. Lang JE. Obesity and asthma in children: current and future therapeutic options. Paediatr Drugs. 2014;16(3):179-88.

7. da Silva PL, de Mello MT, Cheik NC, et al. Interdisciplinary therapy improves biomarkers profile and lung function in asthmatic obese adolescents. Pediatr Pulm. 2012;47(1):8-17.

8. Lin JH. Normocaloric diet improves asthma-related quality of life in obese pubertal adolescents. Pediatrics. 2014;134 Suppl 3:S170-1.

9. Spriet SW, Davis KL. Diet-induced weight loss in obese children with asthma: a randomized controlled trial. Pediatrics. 2014;134 Suppl 3:S170.

10. Martin MA, Mosnaim GS, Olson D, et al. Results from a community-based trial testing a community health worker asthma intervention in Puerto Rican youth in Chicago. J Asthma. 2014;27:1-12.

11. Warnecke RB, Oh A, Breen N, Gehlert S, Paskett E, Tucker KL, Lurie N, Rebbeck T, Goodwin J, Flack J, Srinivasan S, Kerner J, Heurtin-Roberts S, Abeles R, Tyson FL, Patmios G, Hiatt RA. Approaching health disparities from a population perspective: the National Institutes of Health Centers for Population Health and Health Disparities. Am J Public Health. 2008;98(9):1608-15.

12. Bandura A. Self-efficacy: toward a unifying theory of behavioral change. Psychol Rev. 1977;84:191-215.

13. Martin MA, Olson D, Mosnaim GS, et al. Recruitment, asthma characteristics, and medication behaviors in Midwest Puerto Rican Youth: data from project CURA. Ann Allerg Asthma Im. 2012;109:121-7.

14. Liu AH, Zeiger R, Sorkness C, et al. Development and cross-sectional validation of the childhood asthma control test. J Allergy Clin Immunol. 2007:119(4):817-25.

15. Expert Panel Report 3. Guidelines for Diagnosis and Management of Asthma. National Asthma Education and Prevention Program, 2007. Available at https://www.ncbi.nlm.nih.gov/books/NBK7232/. Accessed 21 Oct 2013.

16. Bender BG, Wamboldt FS, O'Connor SL, et al. Measurement of children's asthma medication adherence by self-report, mother report, canister weight, and Doser CT. Ann Allerg Asthma Im. 2000;85:416-21.

17. American College of Chest Physicians. The American College of Chest Physicians Patient Education Guide: using your MDI with a spacer. 2006. Web site. Available at http://www.chestnet.org/Publications/OtherPublications/Patient-Education-Guides. Accessed 18 Oct 2013.

18. Martin MA, Thomas AM, Mosnaim GS, et al. Home asthma triggers: barriers to asthma control in Chicago Puerto Rican children. J Health Care Poor U. 2013;24(2):813-27.

19. Kumar R, Curtis LM, Khiani S, et al. A community-based study of tobacco smoke exposure among inner-city children with asthma in Chicago. J Allergy Clin Immunol. 2008;122(4):754-9.

20. Lakshmy R, Gupta R. Measurement of glycated hemoglobin A1c from dried blood by turbidimetric immunoassay. J Diabetes Sci Technol. 2009;3(5): 1203-6.

21. Kapur S, Kapur S, Zava D. Cardiometabolic risk factors assessed by a finger stick dried blood spot method. J Diabetes Sci Technol. 2008;2(2):236-41.

22. Evenson KR, Catellier DJ, Gill K, et al. Calibration of two objective measures of physical activity for children. J Sports Sci. 2008;26(14):1557-65.

23. Janz KF, Lutuchy EM, Wenthe $P$, et al. Measuring activity in children and adolescents using self-report: PAQ-C and PAQ-A. Med Sci Sports Exerc. 2008;40(4):767-72 
24. Fulkerson JA, Nelson MC, Lytle LA, et al. The validation of a home food inventory. Int J Behav Nutr Phys Act. 2008;5:55.

25. Ihmels MA, Welk GJ, Eisenmann JC, et al. Development and preliminary validation of a Family Nutrition and Physical Activity (FNPA) screening tool. Int J Behav Nutr Phys Act. 2009;6:14.

26. U.S. Household Food Security Survey Module: Three-Stage Design, with Screeners. Economic Research Service, USDA. July 2008. Available at https://www.ers.usda.gov/topics/food-nutrition-assistance/food-securityin-the-us/surveytools/. Accessed 29 Nov 2016.

27. Chervin RD, Hedger K, Dillon JE, et al. Pediatric Sleep Questionnaire (PSQ): validity and reliability of scales for sleep-disordered breathing, snoring, sleepiness, and behavior problems. Sleep Med. 2000;1:21-32.

28. Bursch B, Schwankovsky L, Gilbert J, et al. Construction and validation of four childhood asthma self-management scales: parent barriers, child and parent self-efficacy, and parent belief in treatment efficacy. J Asthma. 1999:36:115-28.

29. Kroenke K, Spitzer RL, Williams JB. The PHQ-9: validity of a brief depression severity measure. J Gen Intern Med. 2001;16(9):606-13.

30. Lang AJ, Stein MB. An abbreviated PTSD checklist for use as a screening instrument in primary care. Behav Res Ther. 2005;43(5):585-94.

31. Child Depression Inventory 2 Short Form. Available at http://www.mhs.com/ product.aspx?gr=edu\&prod=cdi2\&id=overview. Accessed 15 May 2015.

32. Voorend-van Bergen $\mathrm{S}$, Vaessen-Verberne AA, Landstra AM, Brackel HJ, van den Berg NJ, Caudri D, de Jongste JC, Merkus PJ, Pijnenburg MW. Monitoring childhood asthma: web-based diaries and the asthma control test. J Allergy Clin Immunol. 2013;133:1599-605. e2.

33. Postma J, Smalley K, Ybarra V, Kieckhefer G. The feasibility and acceptability of a home visitation, asthma education program in a rural, Latino/a population. J Asthma. 2001:48(2):139-46.

34. Campbell JD, Brooks M, Hosokawa P, Robinson J, Song L, Krieger J. Community health worker home visits for Medicaid-enrolled children with asthma: effects on asthma outcomes and costs. Am J Public Health 2015;105(11):2366-72.

35. Ogden CL, Carroll MD, Kit BK, et al. Prevalence of childhood and adult obesity in the United States, 2011-2012. JAMA. 2014;311(8):806-14.

36. Ford AL, Hunt LP, Cooper A, et al. What reduction in BMI SDS is required in obese adolescents to improve body composition and cardiometabolic health? Arch Dis Child. 2010:95(4):256-61.

37. Goodwin RD, Bandiera FC, Steinberg D, et al. Asthma and mental health among youth: etiology, current knowledge and future directions. Expert Rev Respir Med. 2012;6(4):397-406.

38. Gundersen C, Lohman BJ, Garasky S, et al. Food security, maternal stressors, and overweight among low-income US children: results from the National Health and Nutrition Examination Survey (1999-2002). Pediatrics. 2008; 122(3):e529-40.

39. Farr OM, Sloan DM, Keane TM, et al. Stress- and PTSD-associated obesity and metabolic dysfunction: a growing problem requiring further research and novel treatments. Metabolism. 2014;63(12):1463-8.

40. Stacciarini JM, Rosa A, Ortiz M, et al. Promotoras in mental health: a review of English, Spanish, and Portuguese literature. Fam Community Health. 2012;35(2):92-102.

41. Postma J, Karr C, Kieckhefer G. Community health workers and environmental interventions for children with asthma: a systematic review. J Asthma. 2009;46(6):564-76.

\section{Submit your next manuscript to BioMed Central and we will help you at every step:}

- We accept pre-submission inquiries

- Our selector tool helps you to find the most relevant journal

- We provide round the clock customer support

- Convenient online submission

- Thorough peer review

- Inclusion in PubMed and all major indexing services

- Maximum visibility for your research

Submit your manuscript at www.biomedcentral.com/submit

) Biomed Central 